\title{
Microbiological Profile of Urinary Tract Infections at a Tertiary Care Hospital
}

\author{
K.N. Ravichitra* and U. Srinivasa Rao \\ Department of Microbiology, ASRAM Medical College, Eluru- 534005, \\ West Godavari dist, Andhra Pradesh, India \\ *Corresponding author
}

\section{A B S T R A C T}

\section{Keywords}

Microbiological

Profile,

Urinary Tract

Infections,

Bacteriuria

\section{Article Info}

Accepted:

15 April 2019

Available Online:

10 May 2019
Urinary tract infection (UTI) is one of the more common medical problems. It is an inflammatory response of the urothelium to bacterial invasion that is usually associated with bacteriuria and pyuria. Common disorder is accounting for 1-3\% of consultations in general medical practice. A total of 3835 urine samples collected from clinically suspected urinary tract infection were subjected to microbiological investigations. Out of 3835 urine samples processed, 1756 (45.8\%) samples showed significant growth. Escherichia coli $(48.9 \%)$ was the most common organism isolated followed by Klebsiella (32.6\%). Our study showed that majority $(61.2 \%)$ of the positive samples belonged to 21-40 years. Sensitivity to nitrofurantoin and amikacin was good in our study when compared to other drugs. This study shows the isolation rate of various uropthogens and their sensitivity to commonly used drugs for the treatment of UTI.

\section{Introduction}

Urinary tract infection (UTI) is a term that is applied to a variety of clinical conditions ranging from asymptomatic presence of bacteria in the urine to severe infection of the kidney with resultant sepsis. ${ }^{1}$ Urinary tract infections may involve just the lower tract or both the lower and upper tracts. ${ }^{2}$ They are a common cause of morbidity and can lead to significant mortality. They account for $1-2 \%$ of all office visits by women and $0.6 \%$ of all office visits by men. ${ }^{3}$ The uropathogens causing UTI vary by clinical syndrome but are usually enteric gram negative rods that have migrated to the urinary tract. ${ }^{4}$ Most common organisms in community include Escherichia coli, Proteus species, Pseudomonas species, Streptococci and Staphylococcus epidermidis. ${ }^{5}$ In hospital acquired UTIs a wider variety of causative organisms are found though Escherichia coli still predominates. The incidence of bacteriuria also increases with institutionalization or hospitalization and concurrent disease. Most UTIs are caused by 
a single bacterial species. Choosing judiciously whether to initiate antibiotic therapy and then selecting the most urinary focused agent for the shortest appropriate duration are important factors in global efforts to stem the rise of antimicrobial resistant organisms.

The available data demonstrates a worldwide increase in the resistance to antibiotics commonly used to treat UTI.

Hence this study was undertaken to identify various etiological agents causing urinary tract infection, to evaluate antimicrobial susceptibility pattern of those isolates, to study the effect of age and sex in the causation of UTI.

\section{Materials and Methods}

This is an observational study conducted in the Department of Microbiology, ASRAM, Eluru. Urine samples of both inpatients and outpatients of clinically suspected urinary tract infections received in the department for aerobic culture and sensitivity during January 2018 and December 2018, of both sexes and of all age groups were included in the study. Mid stream urine collected in a sterile wide mouthed container was processed.

After preliminary screening by Gram staining, isolation of urinary pathogens was done on MacConkey and blood agar by surface streak procedures using calibrated loops for semiquantitative method. ${ }^{6,7}$ Confirmation of the isolated organism was done by Gram staining, hanging drop method of motility testing, catalase, oxidase and other biochemical reactions.

\section{Antibiotic sensitivity testing}

Was performed according to CLSI guidelines on Muller-Hinton agar by Kirby-Bauer disc diffusion method. Commercially available antibiotic discs of Himedia were used.

\section{Results and Discussion}

A total of 3835 urine samples were considered for the study, of them 2560 were from outpatients and 1275 from inpatients. Of the total samples significant growth was seen in 1756 samples $(45.8 \%)$. Of the positive samples $502(28.6 \%)$ were males and 1254 (71.4\%) were females. Sex wise distribution of the positive samples is shown in the table 1. Gram negative organisms $1510(85.9 \%)$ predominated in our study in comparison to the gram positive organisms 246 (14\%). 1377 $(91.2 \%)$ of 1510 samples belonged to enterobacteriaceae family. Various uropathogens isolated is shown in the chart 1.Our study showed that majority 1075 $(61.2 \%)$ of the positive samples belonged to 21-40 years. Age wise distribution of the positive samples is shown in the chart 2 . Sensitivity to nitrofurantoin $90.5 \%$ and amikacin $87 \%$ was good in our study, followed by ciprofloxacin $87 \%$. Sensitivity to ceftriaxone and ceftazidime was moderate in our study. Whereas sensitivity to amoxyclav was only $32.4 \%$. All the Gram positive organisms showed low resistance to linezolid. UTIs are the result of interactions between the uropathogens and the host. $45.8 \%$ of samples showed growth of various pathogens in our study which is similar to Ruchi Mishra et al., $43.6 \% .^{9}$ Positivity of females in our study was $71.4 \%$ which is similar to the study conducted by Latika Jshch et al., $77.40 \% .{ }^{10} 61.2 \%$ of positive samples in our study were of the age group 21-40 years, similar to Shamataj Kattalagere Razak et al., ${ }^{11}$ Gram negative organisms predominated in our study in comparison to gram positive organisms, which is similar to other studies. Escherichia coli $43.9 \%$ is the predominant uropathogen in our study which is similar to Salwa $\mathrm{H}$. Alkhyat et al., $45.2 \%{ }^{12}$ 
Table.1 Sex wise distribution of positive samples

\begin{tabular}{|l|c|c|}
\hline Sex & No of positives & \% of positives \\
\hline Males & 502 & 28.6 \\
\hline Females & 1254 & 71.4 \\
\hline Total & 1756 & 100 \\
\hline
\end{tabular}

Chart.1 Various uropathogens isolated

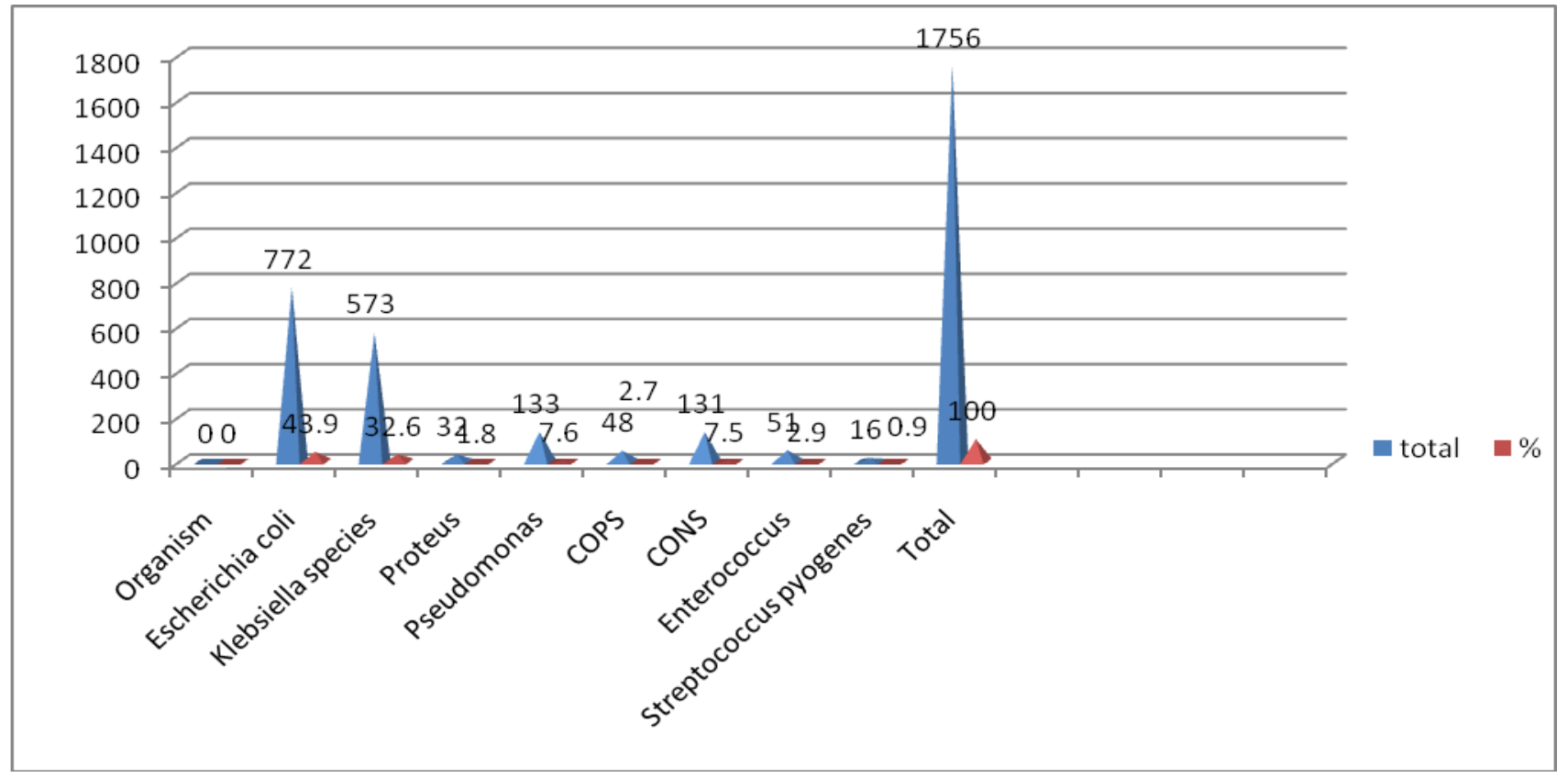

Chart.2 Age wise distribution of positive samples

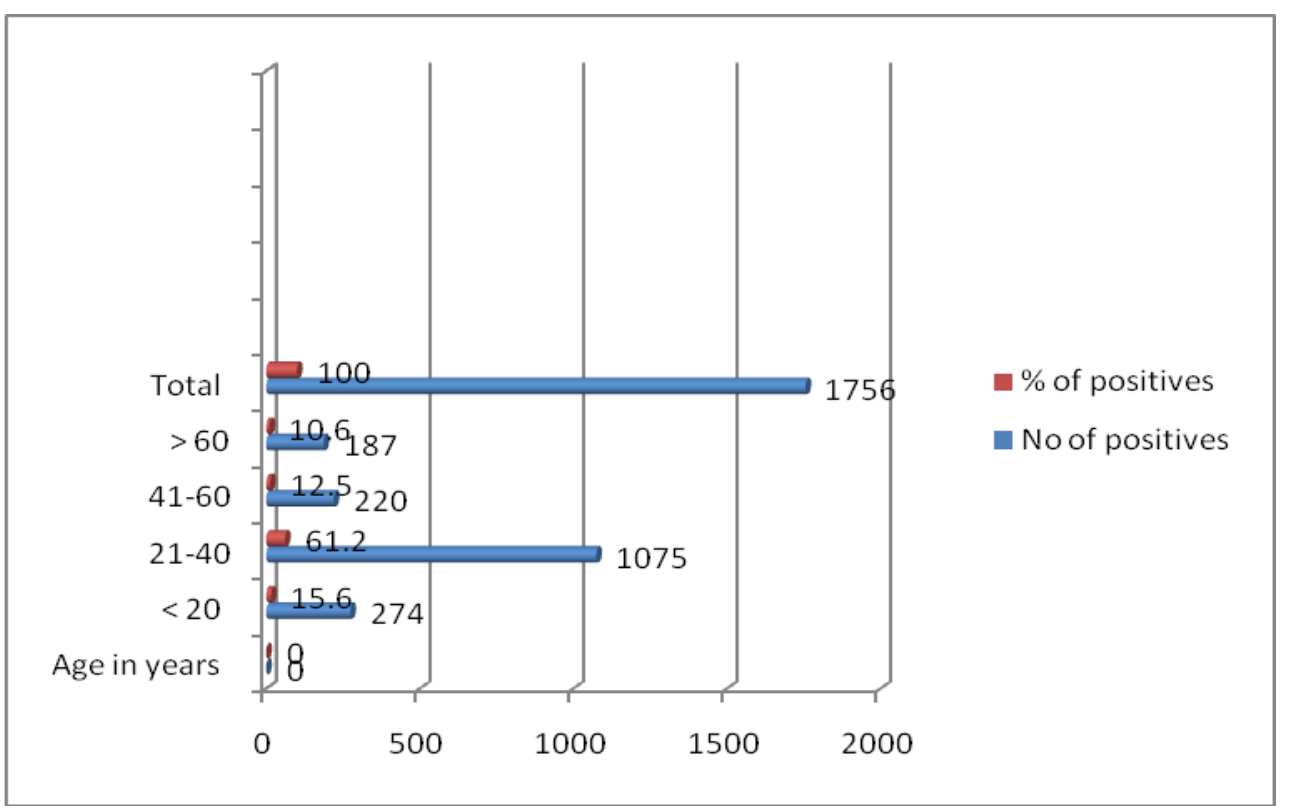


The present study also showed $32.6 \%$ of the isolates were Klebsiella, similar to Akhilesh kumar et al., $32.8 \% .{ }^{13}$ Our study showed that there is increasing rate of isolation of klebsiella as uropathogen. Proteus species constituted only $1 \%$ of isolates in our study which is almost similar to Bhatt CP et al., ${ }^{14}$ $7.6 \%$ of the isolates in our study belonged to pseudomonas aeruginosa, while Iregbu et al., reported $8.4 \% .{ }^{15}$ Isolation of Coagulase Positive Staphylococci as uropathogen in our study was $2.7 \%$ while Preethishree et al., reported $3.97 \%$. The present study showed that sensitivity to nitrofurantoin and amikacin was good, similar to the study conducted by Vasuki Balasubramanyam. ${ }^{17}$

In conclusion, treatment of UTI accounts for a major proportion of antimicrobial use in ambulatory care, inpatient care and long term care settings. Responsible use of antibiotics for this common infection has broad implications for preserving antibiotic effectiveness into future.

\section{References}

1. Emil A Tanagho, Jack W Mc Aninch. 2009. Smith's General Urology: $17^{\text {th }}$ edition,193-197.

2. Geo F. Brooks., Karen C. Carroll et al., 2007. Jawetz, Melnick \& Adelberg's Medical Microbiology. $24^{\text {th }}$ edition, 743747.

3. Anthony J Schaeffer., Edward M. Schaeffer. 2012.Campbell -Walsh Urology. $10^{\text {th }}$ edition, 257-262.

4. Kalpana Gupta., Barbara W. 2018. Harrisons's Principles of Internal Medicine. $20^{\text {th }}$ edition, 968-970.

5. B Conway et al., 2018. Davidson's Principles and Practice of Medicine. $23^{\text {rd }}$ edition, 426-429.

6. J. Gerald Collee., Barrie P. Marmion et al., 2012. Mackie \& Mc Cartney:
Practical Medical Microbiology: 14th edition, 413-418.

7. Elmer W. Koneman et al., 2006. Color Atlas and Textbook of Diagnostic Microbiology. 6th edition. Baltimore: Lippincott Williams Wilkins.

8. Franklin R. Cockerill. 2012. CLSI Performance Standards for Antimicrobial Disk Susceptibility Tests; Approved Standard: Eleventh Edition. CLSI document M02-A11.

9. Ruchi Mishra et al., 2016. Bacteriological profile and sensitivity pattern of microorganisms causing Urinary Tract Infection at a tertiary care center in eastern Uttar Pradesh. International Journal of Biomedical and Advance Research. 7(6), 292-297.

10. Latika J Shah et al., 2015. Urinary tract infection: Bacteriological profile and its antibiotic susceptibility in western India. National Journal of Medical Research. 5 (1), 71-74.

11. Razak SK and Gurushantappa V. 2012. Bacteriology of urinary tract infection and antibiotic susceptibility pattern in a tertiary care hospital in South India. Int J Med Sci Public Health. 1(2), 109-112.

12. Salwa H. Alkhyat and Maher Ali Al.Maqtari. 2014. Prevalence of Microorganisms isolates from Urinary Tract Infections at Some Hospitals in Sana'a City, Yemen. Int.J.Curr. Microbiol.App.Sci 3(6), 876-885.

13. Akhilesh Kumar and Rajiv Kumar et al., 2017. Antimicrobial susceptibility pattern of urine culture isolates in a tertiary care hospital of Jharkhand, India. International Journal of Basic \& Clinical Pharmacology. 6 (7), 1733-9.

14. Bhatt CP., Shrestha et al.,2012.Etiology of Urinary tract infection and drug resistance cases of Uropathogens. Journal of Kathmandu Medical College, 1,2( 2), 114-120. 
15. Iregbu $\mathrm{KC}$ et al., 2013.Urinary tract infections in a tertiary hospital in Abuja, Nigeria. African journal of clinical and experimental microbiology. 14(3), 169173.

16. Preethishree et al., 2016. Uropathogens and their Antibiotic Susceptibility Pattern at a Tertiary Care Teaching Hospital in Coastal Karnataka, India.
Int.J.Curr.Microbiol. App.Sci. 5(1), 2331.

17. Balasubramanyam V and Sharma NL. 2017. Clinical profile and gram negative bacterial profile of urinary tract infection in children attending a tertiary care hospital of Tamilnadu, India. Int $\mathbf{J}$ Contemp Pediatr 4(1), 231-3.

\section{How to cite this article:}

Ravichitra, K.N. and Srinivasa Rao, U. 2019. Microbiological Profile of Urinary Tract Infections at a Tertiary Care Hospital. Int.J.Curr.Microbiol.App.Sci. 8(05): 1771-1775. doi: https://doi.org/10.20546/ijcmas.2019.805.205 